\title{
Modeling for optimal management of agricultural and domestic wastewater loading to streams
}

\author{
Muhammad Shafqat Ejaz \\ Agricultural Engineering and Water Management, Agriculture Department, Government of Sindh \\ Karachi, Pakistan
}

Richard C. Peralta

Biological and Irrigation Engineering Depastment, Utah State University, Logan

\begin{abstract}
A simulation/optimization ( $\mathrm{S} / \mathrm{O}$ ) model to aid managing multiobjective wastewater loading to streams while maintaining adequate downstream water quality is presented. The conflicting objectives are to maximize the human and dairy cattle populations from which treated wastewater can be discharged to the river system. Nonindustrial municipal (domestic) wastewater undergoes primary and secondary treatment by a sewage treatment plant (STP) before entering as a steady point source. Dairy wastewater is treated by overland flow (OLF) land treatment before entering the stream as a controlled steady diffuse source. Maximum dual-source loading strategies which do not degrade downstream water quality beyond specified limits are developed. For each computed loading strategy, an optimal OLF system design is also determined. The E constraint method is used to obtain sets of noninferior solutions. Sets of noninferior solutions are represented graphically to show the trade-off between human and bovine populations that can be maintained. Each set is computed for a different upstream flow rate to illustrate sensitivity to nondeterministic upstream flow rates. The nonlinear constraints utilized restrict downstream concentrations of 5-day biochemical oxygen demand, dissolved oxygen, nitrogen (organic, ammonia, nitrite, and nitrate), organic and dissolved phosphorus, and chlorophyll $a$. Concentrations are described via regression equations. The new regression expressions, surrogates for the complex advective-dispersive equation, permit rapid and feasible solutions by this unique $\mathrm{S} / \mathrm{O}$ model.
\end{abstract}

\section{Introduction}

Historically, streams and land receive wastewater generated by agricultural and nonagricultural activitics. Pollution can enter surface water through point and nonpoint sources. Point sources are considered to have single discharge locations which can be regulated [Thomann and Mueller, 1987]. Nonpoint sources (NPS) are considered to be diffused. Flows from agriculture are common nonpoint sources. The environmental impacts of these discharges have been a matter of concern. Pollutant discharge into the environment has affected public health and caused adverse conditions [Metcalf and Eddy Inc., 1991]. The resulting downstream concentrations of biochemical oxygen demand (BOD), dissolved oxygen (DOX), nutrients (nitrogen and phosphorus), and chlorophyll $a$ (for assessment of eutrophication level) are important and are modeled in this research.

Many surface water quality management models have been reported in the literature. Both deterministic and probabilistic optimization models are common. Thomann and Sobel [1964], Loucks et al. [1967], and Greaves et al. [1972] used linear programming, while Liebman and Lynn [1966] and Shih [1970] used dynamic programming for deterministic water quality modeling. Loucks and Lynn [1966], DeLucia et al. [1978], Ellis

Copyright 1995 by the American Geophysical Union.

Paper number 94WR02980.

0043-1397/95/94WR-02980\$05.00
[1987], Burn [1989], and Cardwell and Ellis [1993] addressed the randomness inherent in the water quality process. Variability in natural physical, chemical, and biological systems and variability due to inexact measurements of water quality variables can affect exact prediction of stream water quality [Burn and McBean, 1985]. Many researchers considered stream inflows, reaction rate constants, and waste strength and concentration as random variables in their stochastic optimization models. This paper does not address probabilistic considerations in stream water quality.

Modelers for management frequently employ steady state simulation of stream water quality for low flow periods. They usually evaluate the effect of waste loading on stream water quality while the stream is at the 7-day average minimum flow occurring once in 10 years (7Q10) [Loucks and Lynn, 1966]. Accordingly, this paper uses steady state simulation and optimizes stream water quality management for assumed low flow periods. We also show the sensitivity of optimal strategies to nondeterministic stream inflows.

The stream water quality optimization models reported to date have been limited to constraining BOD and DOX and have incorporated the oxygen sag (Streeter-Phelps) equation or modifications thereof. Those models have addressed single or multiple point sources but have not considered spatially varied or nonpoint source waste loading. Letson [1992], Letson et al. [1993], and Elmore et al. [1985] have identified trade-offs between point and nonpoint source waste loading. These stud- 
ies considered NPS waste loading from the land use practices around the water bodies.

This work expands previous optimization studies by considering NPS as well as point source loading and by illustrating how to practically constrain a wide variety of water quality parameters. The presented multiobjective simulation/optimization $(\mathrm{S} / \mathrm{O})$ model is applied to a stream system which is receiving a point source (nonindustrial municipal (domestic) wastewater, after primary and secondary treatment in s sewage treatment plant (STP)) and a nonpoint source (dairy wastewater after it has been treated by an overland flow (OLF) natural treatment system).

The computer model seeks to maximize the human population $\left(Z_{1}\right)$ and maximize the number of cows $\left(Z_{2}\right)$ which can provide treated waste to the stream without degrading downstream water quality beyond specified limits. The two objectives conflict because an increase in human-generated waste loading to the stream will require a decrease in bovinegenerated waste loading and vice versa. To present the model in an orderly fashion, we next describe S/O modeling, surface water quality models, OLF systems, and multiobjective programming.

An S/O model combines both simulation equations and optimization-type control theory to calculate optimal solutions to water resources problems. One complex S/O modeling approach links an external simulation model with an optimization algorithm. The simulation model is invoked repeatedly to develop a Jacobian matrix [Gorelick et al., 1984]. This approach has been reported to be very computationally intensive [Ahlfeld et al., 1986; Alley, 1986].

Other S/O nodels use an embedding approach. These models contain as constraints discretized finite difference or finite element approximations of flow and transport equations. Such embedding models are commonly used for groundwater management [Willis and Yeh, 1987]. Concerning contaminant management, the embedding approach has been shown to be useful for optimizing contaminant injection into an aquifer [Gorelick and Remson, 1982], optimizing diffuse groundwater contamination management [Gharbi and Peralta, 1994], and optimizing vadose zone pesticide management [Peralta et al., 1994]. However, the embedding of finite difference or finite element expressions within S/O models for surface water contaminant transport has not been reported.

Some of the embedding models reported above included thousands of linear, nonlinear, and/or piecewise linear constraint equations and were very challenging and timeconsuming to solve. To reduce the size of the optimization problem and to avoid the high computational burden of both linking and embedding approaches while still addressing nonlinear transport proccsses, Alley [1986] used regression equations.

Alley developed regression equations expressing contaminant transport in groundwater and embedded these in a nonlinear optimization problem formulation. Each regression equation was developed by evaluating the results of several transport simulation runs. Runs differed via discrete changes in the values of decision variables. The regression expressions developed estimated the concentration at critical locations as functions of pumping and recharge at wells. Since then, several others [Lefkoff and Gorelick, 1990; Cooper, 1994] have used regression expressions for groundwater management. The use of this approach within surface water quality S/O models has not been reported previously.
No surface water S/O model constraining quality parameters other than BOD and DOX has been reported. However, simulation models that calculate changes in concentration of many constituents simultaneously are fairly common. With simulation models alone, it can be very difficult to determine acceptable loading strategies while attempting to satisfy many water quality criteria simultaneously. Thus an S/O modeling approach and model that have this capability are needed. Developing and demonstrating these is the focus of this study.

QUAL2E [Brown and Barnwell, 1987], a U.S. Environmental Protection Agency (EPA) simulation model, is used worldwide by consultants and regulatory agencies for simulating stream water quality. The simulation abilities of QUAL2E are detailed and complex. Among the simulated rate processes are ammonia decay and benthos source production; BOD aerobic decay and settling; coliform die-off; nitrification; nonconservative material decay and settling; organic nitrogen decay and settling; background phosphorus benthos source production and sediment oxygen demand; reaeration; and algal growth, production, respiration, and settling. All of these processes can be incorporated within the S/O model presented via simplified regression equations.

Some of the constituents entering the stream originate from dairy cows. The dairy waste stream passes through an overland flow (OLF) treatment prior to entering the stream. OLF is a relatively simple soil-based natural treatment system which is inexpensive to operate. The system consists of a number of vegetated, uniformly sloped terraces, with wastewater applied at the top of the terrace through a distribution system. Effluent runoff is collected in the channel at the bottom [U.S. Environmental Protection Agency, 1992]. The application rate is maintained in such a way that it causes sheet flow over the terrace. Water is lost primarily by evapotranspiration but also by deep percolation. Most of the applied water is collected as surface runoff. Microbial activity at the soil surface removes pollutants and seals the soil surface somewhat with a slime which helps prevent deep percolation. The S/O model presented determines the optimal length and unit application rate to the OLF terrace.

In an OLF treatment system, physical, chemical, and biological processes occur simultaneously to remove pollutants at natural rates. In a sewage treatment plant (STP), these processes occur sequentially at higher rates with the input of energy [Metcalf and Eddy Inc., 1991]. Physical (screening, sedimentation, flocculation, etc.) unit operations and some of the chemical (precipitation and adsorption) and biological (activated sludge system) unit processes provide primary and secondary treatment to influent to the STP [Metcalf and Eddy Inc., 1991].

Multiple conflicting goals of management problems can be addressed by using multiobjective programming (MOP). MOP determines the best compronise levels of conflicting goals simultaneously [Datta and Peralta, 1986]. The selection of best compromise levels of conflicting goals is carried out with the aid of a decision maker(s). This study is aimed at presenting the best compromise levels of $Z_{1}$ and $Z_{2}$.

MOP methods are classified as either generating methods or preference-oriented methods, depending on the decisionmaking process [Cohon, 1978]. In a generating method, an analyst develops a range of choices and trade-offs among objectives and presents it graphically or in tabular form to a decision maker. A preference-oriented method requires that 
the decision makers articulate their preferences and pass that information on to the analyst [Cohon, 1978].

A generating method technique is used in this study to solve the multiobjective problem. Specification of objectives, generation of plans, and plan selection are the steps of this MOP method. The plans are generated by the E constraint method [Cohon and Marks, 1975]. In the E constraint method, one objective is optimized while other objectives are constrained to some value. The objective of maximizing the human population is included conventionally as an objective function. The bovine population objective serves as a tight constraint.

The optimal solution to a MOP problem is called a noninferior solution. A noninferior solution is a solution for which the increase in the value of one objective will require decreases in the values of other objectives [Loucks et al., 1981]. The sets of noninferior solutions are presented graphically for different upstream flow rates. Such figures show a range of choices and trade-offs and can assist decision makers in plan selection.

\section{Model Development}

The S/O model developed here is applied to a hypothetical study area (Figure 1). The principal objective is to maximize the human population $\left(Z_{1}\right)$ from which a stream system can satisfactorily assimilate the waste. Generated wastewater is discharged to the stream after it has been treated by a sewage treatment plant (STP). The selcction of $Z_{1}$ as the principal objective is arbitrary and does not represent management prefcrence. $Z_{1}$ is the result of dividing the optimal steady flow rate through the STP ( $Q_{1}^{p}$, in cubic meters per second) by a fixed per capita waste generation rate $\left(q^{P}\right.$, in cubic meters per second per capita).

$$
\max Z_{1}=Q_{1}^{p} / q^{p}
$$

The model is solved subject to a set of constraints including a lower bound $\left(Z_{2}^{l}\right)$ on the constraint objective $\left(Z_{2}\right)$. Although this objective represents the number of dairy cows, it is expressed in terms of the rate of waste flow entering the OLF $\left(Q^{d i}\right.$, in cubic meters per second) and the unit flow rate $\left(q^{d i}\right.$, in cubic meters per second per animal unit) generated in the dairy. The unit flow rate for dairies is usually expressed in terms of animal unit ( $1 \mathrm{AU}=1000$ pounds $(453.6 \mathrm{~kg})$ ), and therefore a conversion factor, $f^{c \prime \prime}$, is used to convert animal units to number of dairy cows. The constrained second objective is represented as

$$
Q^{d i} / f^{c t} q^{d i}=Z_{2} \geq Z_{2}^{L}
$$

To construct one set of noninferior solutions, the model is solved several times, each time with a different value of $Z_{2}^{L}$. Within the feasible solution space, the constrained objective will be binding. The range of $Z_{2}$ is from $Z_{2}$ at $\max Z_{1}$ to maximum $Z_{2}$. The noninferior solution set is developed by systematically changing $Z_{2}^{L}$ from one extreme to the other while computing an optimal loading strategy for each value of $Z_{2}^{L}$ used.

The modeled and constrained constituents (and the abbreviations used here) are 5-day biochemical oxygen demand $\left(\mathrm{BOD}_{5}\right)$, organic nitrogen $(\mathrm{OGN})$, ammonia nitrogen $\left(\mathrm{NH}_{3}\right)$, nitrite nitrogen $\left(\mathrm{NO}_{2}\right)$, nitrate nitrogen $\left(\mathrm{NO}_{3}\right)$, total nitrogen (TON), organic phosphorus (OGP), dissolved phosphorus (DSP), total phosphorus (TOP), chlorophyll a (CHA), and dissolved oxygen (DOX). Waste load maximization for these

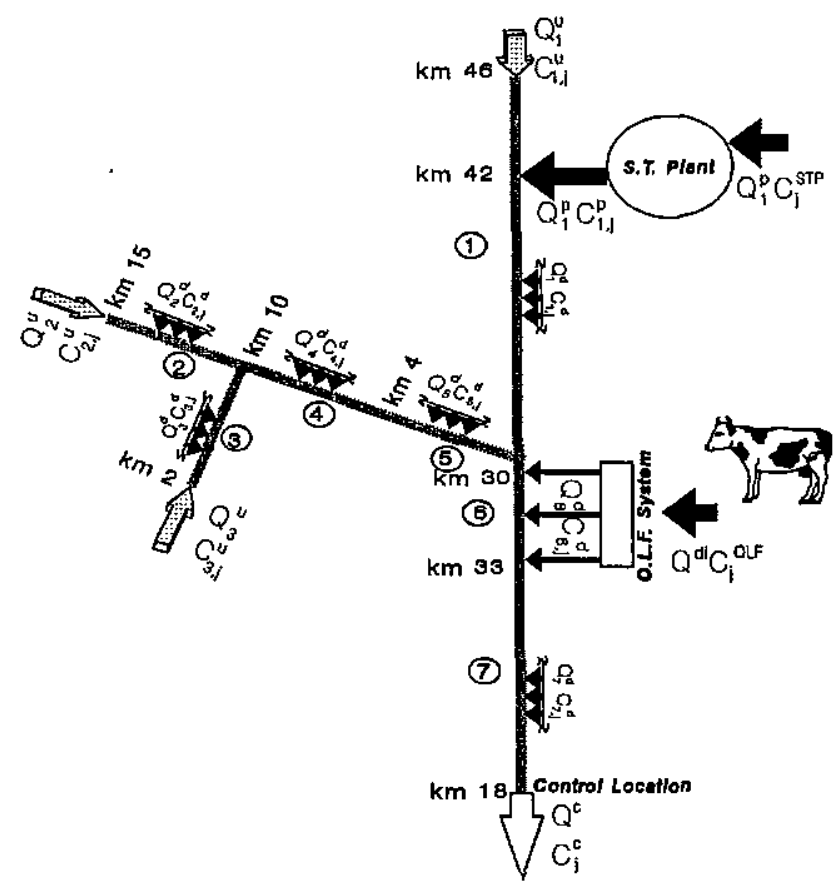

Figure 1. Study area schematic. S.T., sewage treatment; O.L.F., overland flow.

constituents is limited by the assimilative capacity of the receiving stream (a function of unknown flow rates), surface water quality targets, and treatment system capabilities. Here, the water quality targets are dependent on intended water use. These limitations are expressed as constraints and bounds and delineate the feasible solution space.

The flow rate at the control location, $Q^{c}$, is calculated by continuity:

$$
Q^{c}=\sum_{i=1}^{r} Q_{i}^{d}+\sum_{i=1}^{h} Q_{i}^{\prime \prime}+Q_{1}^{p}
$$

where $Q_{i}^{d}$ is the nonpoint source flow rate in reach $i$ (in cubic meters per second) and $Q_{i}^{u}$ is the inflow rate at the most upstream reach of stream branch $i$ (in cubic meters per second). Here and later, the superscripts $c, d ; u$, and $p$ refer to the downstream control location, NPS reach, headwater location, and point source, respectively. In Figure 1, NPS reaches 1 through 5 and 7 contribute water of fixed base flow and concentration. In reach 6 , flow and mass loading rates from the OLF system are the unknowns being optimized.

Here, the assimilative capacily of a stream for a $j$ th constituent is represented by a regression equation. The equation predicts the result of steady loading, interaction with other constituents, and advective-dispersive fate and transport. In fact, the regression expression represents all the processes incorporated in QUAL2E.

The regression equations are prepared based on data obtained from numerous systematic QUAL2E simulations. Of al] forms of regression equations examined, the one having this mass balance form best fits the data (details of preparing regression equations are given in the subsequent section): 
Table 1. List of Decision and State Variables and Fixed Values

\begin{tabular}{|c|c|c|}
\hline Source/Location & Decision and State Variables & Fixed Values \\
\hline Point source (STP) & flow rate, population* & $\begin{array}{l}\text { per capita flow, removal efficiencies, } \\
\text { domestic (nonindustrial } \\
\text { municipal) waste characterization, } \\
\text { and effiuent concentrations }\end{array}$ \\
\hline $\begin{array}{l}\text { Nonpoint source: } \\
\text { OLF reach }\end{array}$ & $\begin{array}{l}\text { flow rate, number of cows, } \\
\text { BOD effluent } \\
\text { concentration, BOD } \\
\text { removal efficiency, length } \\
\text { of OLF system, and } \\
\text { application rate to OLF } \\
\text { terrace }\end{array}$ & $\begin{array}{l}\text { Unit flow rate, dairy waste } \\
\text { characterization (supernatant } \\
\text { from anaerobic lagoon), width of } \\
\text { OLF system, BOD background } \\
\text { concentration, removal } \\
\text { efficiencies (except BOD), } \\
\text { effluent concentrations (except } \\
\text { BOD), OLF system rate } \\
\text { constants, and flow control } \\
\text { parameters }\end{array}$ \\
\hline $\begin{array}{c}\text { Nonpoint source: } \\
\text { other reaches }\end{array}$ & & Flow rate and concentrations \\
\hline $\begin{array}{l}\text { Control site } \\
\text { Upstream }\end{array}$ & flow rate and concentrations & flow rate and concentrations \\
\hline
\end{tabular}

STP, sewage treatment plant; OLF, overland flow; BOD, biochemical oxygen demand.

*Decision variable.

$$
M_{j}^{c}=\beta_{j}^{d} \sum_{i=1}^{r} M_{i, j}^{d}+\beta_{j}^{u} \sum_{i=1}^{h} M_{i, j}^{u}+\beta_{j}^{p} M_{1, j}^{\prime}
$$

where $M_{i, j}^{x}$ is the mass flow rate of the $j$ th constituent in the $i$ th reach of the $x$ th type of source location and is expressed as $M_{i, j}^{x}=Q_{i}^{x} C_{i, j}^{x}$ (in grams per second except for chlorophyll $a$, which is in milligrams per second), $M_{j}^{c}$ is the $j$ th constituent mass flow rate at the control location $\left(M_{j}^{c}=Q^{c} C_{j}^{c}\right)$; $C_{i, j}^{r}$ and $C_{j}^{c}$ are concentrations (in milligrams per liter except for chlorophyll $a$, which is in micrograms per liter); and $\beta_{j}^{x}$ is a regression coefficient describing the contribution of specific mass flow rate to $M_{j}^{c}$.

Equation (5) predicts the dissolved oxygen mass flow rate at a control location as a function of headwater, point, and nonpoint sources and mass flow rates of $\mathrm{BOD}_{5}$, total nitrogen, and chlorophyll $a$ at the control location. No other of the numerous expressions tested predicted DOX nearly as well.

$$
\begin{aligned}
M_{\mathrm{DOX}}^{c}= & \beta_{o}+\beta_{\mathrm{DOX}}^{d} \sum_{i=1}^{r} M_{i, \mathrm{DOX}}^{d t}+\beta_{\mathrm{DOX}}^{u} \sum_{i=i}^{h} M_{i, \mathrm{DOX}}^{u} \\
& +\beta_{\mathrm{DOX}}^{p} M_{1, \mathrm{DOX}}^{p}+\beta_{\mathrm{BOD}}^{c} M_{\mathrm{BOD}}^{c}+\beta_{\mathrm{TON}}^{c} M_{\mathrm{TON}}^{c} \\
& +\beta_{\mathrm{CHA}}^{c} M_{\mathrm{CHIA}}^{c}
\end{aligned}
$$

A stream reach is a stream segment having uniform hydraulic characteristics [Brown and Barnwell, 1987]. Here, the OLF reach (reach 6) is a stream segment which receives steady effluent from the OLF treatment system. We assume that a distribution system is used to release flow steadily from the collection channel in such a diffuse manner that it represents a nonpoint source to the stream along the OLF reach. All other reaches can and do rcceive steady known base flow.

The model computes the optimal flow rate leaving the OLF and its concentration. This flow enters the stream in the OLF reach. The model also computes the optimal number of dairy cows providing waste to the OLF and the length and application rate per unit width to the OLF.

$$
Q_{6}^{d}=Q^{d i} k^{c} k^{t}
$$

where $Q_{6}^{d}$ is the flow rate leaving the OLF system and entering the OLF reach. The factor $k^{c}$ takes into account the water lost from the OLF system due to evapotranspiration and deep percolation. The factor $k^{t}$ is used to convert intermittent OLF operation into a steady wastewater discharge to the stream in the OLF reach. OLF systems are operated intermittently to obtain the best nutrient (especially nitrogen) removal. An application period $\left(O_{\text {nerind }}\right.$ ) of 8 to $16 \mathrm{~h} / \mathrm{d}$ is recommended [Smith and Schroeder, 1985].

Equations (7)-(9) describe the design and operation of an OLF system for settled (primary effluent) wastewater [Smith and Schroeder, 1985]:

$$
q^{\mathrm{OLF}}=\frac{86,400 Q^{d i} \mathrm{FOS}}{W_{\text {design }} O_{\text {period }}}
$$

Equation (7) relates the OLF application rate ( $q^{\text {OLF}}$, in cubic meters per hour per meter), to the total OLF system inflow rate, design width ( $W_{\text {design }}$, in meters), and application period ( $O_{\text {period, }}$ in hours per day). The $W_{\text {design }}$ is a distance parallel to the stream. The design length $(L)$ is perpendicular to the stream and is a parameter being optimized. A factor of safety (FOS) of 1.5 is recommended [Smith and Schroeder, 1985] for safe design of an OLF system.

$$
\begin{gathered}
C_{\mathrm{f}, \mathrm{BOD}}^{d}=C_{\mathrm{BOD}}^{\mathrm{BACK}}+C_{\mathrm{BOD}}^{\mathrm{OLF}} A \exp \left[-k L /\left(q^{\mathrm{OLF}}\right)^{n}\right] \\
A=0.1935+1.3478 q^{\mathrm{OLF}}
\end{gathered}
$$

Equation (8) relates OLF effluent $\mathrm{BOD}_{5}$ concentration $\left(C_{6, \mathrm{BOD}}^{d}\right.$ is also the reach 6 NPS inflow concentration) to influent concentration ( $C$ BOD ), distance downslope $(L)$, OLF application rate, and background concentration $\left(C_{\mathrm{BOD}}^{\mathrm{BACK}}\right)$. $\mathrm{A}$ background concentration of $5 \mathrm{mg} / \mathrm{L}$ has been used, as reported by Smith and Schroeder [1985], because of soil-plant interaction and solubility of organic matter within an OLF system. This is the concentration that will leave the OLF system even if $Q^{d i}$ carries no contaminants. The values of $n$ and $k$ empirically determined by Smith and Schroeder [1985] for primary effluent are assumed here. Based on data [Smith and Schroeder, 1985] for primary effluent, coefficient $A$ is correlated with $q^{\text {OLF }}\left(r^{2}=0.967\right)$ as shown in (9). 
Table 2. Waste Characterization for Domestic Wastewater and Removal Efficiencies for Sewage Treatment Plant (STP)

\begin{tabular}{|c|c|c|c|}
\hline $\begin{array}{c}\text { Constituent* } \\
(j)\end{array}$ & $\begin{array}{c}\text { Influent } \\
\text { (Medium to } \\
\text { Strong, } C_{j}^{\text {STP }), \dagger} \\
\text { mg/L }\end{array}$ & $\begin{array}{c}\text { STP } \\
\text { Efficiency } \\
\left(e_{j}^{p}\right), \uparrow \% \\
\end{array}$ & $\begin{array}{c}\text { Effluent } \\
\left(C_{1, j}^{p}\right), \\
\mathrm{mg} / \mathrm{L}\end{array}$ \\
\hline $\mathrm{BOD}_{5}$ & 310.00 & 90 & 31.00 \\
\hline OGN & 25.00 & 40 & 15.00 \\
\hline $\mathrm{NH}_{3}$ & 37.50 & 15 & 32.00 \\
\hline $\mathrm{NO}_{2}$ & 0.00 & $\cdots$ & $0.20 \ddagger$ \\
\hline $\mathrm{NO}_{3}$ & 0.00 & $\cdots$ & $\cdots$ \\
\hline TON & 62.50 & 10 & 56.25 \\
\hline OGP & 4.00 & 25 & 3.00 \\
\hline DSP & 7.50 & 25 & 5.62 \\
\hline TOP & 11.50 & 25 & 8.62 \\
\hline $\mathrm{CHA}, \mu \mathrm{g} / \mathrm{L}$ & $\cdots$ & $\cdots$ & $4.00 \div$ \\
\hline DOX & $\cdots$ & $\cdots$ & $3.00 \div$ \\
\hline
\end{tabular}

${ }^{*} \mathrm{BOD}_{5}, 5$-day biochemical oxygen demand; OGN, organic nitrogen; TON, total nitrogen; OGP, organic phosphorus; DSP, dissolved phosphorus; TOP, total phosphorus; CHA, chlorophyll $a$; DOX, dissolved oxygen.

†Typical values adopted from Metcalf and Eddy Inc. [1991].

$\ddagger$ Assumed as fixed valucs.

The following equations describe the efficiencies of the STP $\left(e_{j}^{p}\right)$ and OLF system $\left(e_{j}^{d}\right)$ for removal of the $j$ th constituent:

$$
\begin{aligned}
& e_{j}^{p}=\left(C_{j}^{\mathrm{STP}}-C_{\mathrm{l}, j}^{p}\right) / C_{j}^{\mathrm{STP}} \\
& e_{j}^{d}=\left(C_{j}^{\mathrm{OLF}}-C_{6_{i, j}}^{d}\right) / C_{j}^{\mathrm{OLF}}
\end{aligned}
$$

where $C_{j}^{S T P}$ and $C_{j}^{\mathrm{OLF}}$ are the incoming concentrations of the $j$ th constituent in domestic wastewater and dairy wastewater to the respective treatment facilities and $C_{1, j}^{p}$ and $C_{6, j}^{d}$ are the concentrations of the $j$ th constituent leaving the STP and OLF facilities and entering the strcam from those systems, respectively.

Table 1 lists decision and state variables and fixed parameters used in this S/O model. Lower and upper bounds are specified for $Q^{p}, q^{\mathrm{OLF}}, Q_{6}^{d}, C_{6, \mathrm{BOD}}^{d}, L$, and $C_{j}^{c}$ (for all $j$ ). A separate notation list appears at the end of this paper.

\section{Application and Results}

\subsection{Study Area and Assumptions}

The S/O model is applied to a hypothetical seven-reach stream (Figure 1). Table 2 shows the quality of the domestic wastewater entering the STP, STP removal efficiencies, and STP effluent concentrations for various constituents. An EPArecommended daily per capita domestic flow $\left(q^{p}\right)$ of 70 gallons $(270 \mathrm{~L})$ is assumed for the supported suburban community [Metcalf and Eddy Inc., 1991].

Table 3 shows the quality of water entering the OLF system. This is supernatant from an anaerobic lagoon containing settled dairy wastewater. Table 3 also shows removal efficiencies and effluent concentrations for all constituents (except $\mathrm{BOD}_{5}$ ). An OLF operating time $\left(O_{\text {period }}\right)$ of $12 \mathrm{~h} / \mathrm{d}\left(k^{t}=0.5\right)$ and $30 \%$ OLF water loss $\left(k^{c}=0.7\right)$ are assumed. Also assumed is an OLF design width ( $\left.W_{\text {Jesim }}\right)$ of $3000 \mathrm{~m}$ along the stream near the dairies. An average $1500-\mathrm{bb}\left(f^{c \prime \prime}=1.5\right)$ dairy cow generates a unit flow rate of 88.4 gal $\mathrm{AU}^{-1} \mathrm{~d}^{-1}\left(341 \mathrm{~L} \mathrm{AU}^{-1}\right.$ $\mathrm{d}^{-1}$ ) [Soil Conservation Service, 1992]. This includes 66.7 gal $\mathrm{AU}^{-1} \mathrm{~d}^{-1}\left(257 \mathrm{~L} \mathrm{AU}^{-1} \mathrm{~d}^{-1}\right)$ for collecting manure in a flush alley system and $21.7 \mathrm{gal} \mathrm{AU}^{-1} \mathrm{~d}^{\prime} 1\left(84 \mathrm{LAU}^{-1} \mathrm{~d}^{-1}\right)$ as moisture in the excreted manure and milking center wastewater.
Table 3. Waste Characterization for Dairy Wastewater and Removal Efficiencies for Overland Flow (OLF) Treatment

\begin{tabular}{|c|c|c|c|c|}
\hline \multirow[b]{2}{*}{$\begin{array}{c}\text { Constituent } \\
(j)\end{array}$} & \multicolumn{2}{|c|}{$\begin{array}{l}\text { Influent (Supernatant } \\
\text { From Anaerobic } \\
\text { Lagoon, } C_{j}^{\text {OLF }} \text { ) }\end{array}$} & \multirow[b]{2}{*}{$\begin{array}{c}\text { OLF } \\
\text { Efficiency } \\
\left(e_{j}^{d}\right), \dagger \% \\
\end{array}$} & \multirow[b]{2}{*}{$\begin{array}{c}\text { Effluen } \\
\left(C_{6, j}^{d \prime}\right) \\
\mathrm{mg} / \mathrm{L}\end{array}$} \\
\hline & $\begin{array}{c}\text { Pounds } \\
\text { per } 1000 \\
\text { Gallons }\end{array}$ & $\begin{array}{c}\text { Milligrams } \\
\text { per Liter }\end{array}$ & & \\
\hline $\mathrm{BOD}_{5}$ & 2.92 & 350.00 & & \\
\hline OGN & 0.67 & 80.30 & 70 & 24.00 \\
\hline $\mathrm{NH}_{3}$ & 1.00 & 120.00 & 70 & 36.00 \\
\hline $\mathrm{NO}_{2}$ & 0.00 & 0.00 & $\cdots$ & $0.20 \ddagger$ \\
\hline $\mathrm{NO}_{3}$ & 0.00 & 0.00 & $\cdots$ & $\ldots$ \\
\hline TON & 1.67 & 200.00 & 65 & 70.00 \\
\hline OGP & 0.33 & 40.00 & 60 & 16.00 \\
\hline DSP & 0.15 & 17.50 & 40 & 10.80 \\
\hline TOP & 0.48 & 57.50 & 54 & 26.80 \\
\hline CHA, $\mu \mathrm{g} / \mathrm{L}$ & $\cdots$ & $\cdots$ & $\cdots$ & $3.00 \%$ \\
\hline DOX & $\cdots$ & $\cdots$ & $\ldots$ & $4.00 \%$ \\
\hline
\end{tabular}
System

Abbreviations are defined in Table 2.

*Typical values adopted from Soil Conservation Service [1992].

†Typical values adopted from Water Pollution Control Federation

[1990] and U.S. Environmental Protection Agency [1992].

$¥$ Assumed as fixed values.

The concentrations in upstream and diffuse sources (other than the OLF reach) are assumed to be known (Table 4). Table 5 specifies fixed flow rates used in the simulation and/or S/O models. Table 4 also provides imposed water quality criteria. Table 4 shows that, for rigor, combinations of the constituent limits for agriculture, drinking water, aesthetics, and fisheries are used at the control location. Included is Bouwer and Idelovitch's [1987] classification of wastewater use as restricted or unrestricted for irrigation. Bouwer and Idelovitch [1987, p. 517] defined unrestricted irrigation with wastewater as

the use of a high-quality effluent for irrigation of all crops on all types of soil in any area during a prolonged period of time, without adverse effects on crops, soils, animals, people involved in the various stages of the agricultural production process, and consumers.

Table 4. Assumed Fixed Concentrations From Upstream and Diffuse Sources (Other Than OLF Reach) and

\begin{tabular}{|c|c|c|c|}
\hline $\begin{array}{c}\text { Constituent } \\
(j)\end{array}$ & $\begin{array}{c}\text { Upstream } \\
\left(C_{i, j}^{\prime \prime}\right), \mathrm{mg} / \mathrm{L}\end{array}$ & $\begin{array}{c}\text { Diffuse } \\
\text { Sources } \\
\left(C_{i, j}^{d}\right), \mathrm{mg} / \mathrm{L}\end{array}$ & $\begin{array}{l}\text { Maximum Value } \\
\left(C_{j}^{c} \max \right)^{*} \mathrm{mg} / \mathrm{L}\end{array}$ \\
\hline $\mathrm{BOD}_{5}$ & 5.00 & 5.00 & $15.00 \div$ \\
\hline $\mathrm{OGN}$ & 3.00 & 0.00 & 10.00 \\
\hline $\mathrm{NH}_{3}$ & 3.00 & 0.00 & 15.00 \\
\hline $\mathrm{NO}_{2}$ & 0.03 & 0.00 & $1.00 \div$ \\
\hline $\mathrm{NO}_{3}$ & 5.00 & 2.00 & $10.00 \div$ \\
\hline TON & 11.03 & 2.00 & $20.00 \dagger$ \\
\hline $\mathrm{OGP}$ & 0.00 & 1.00 & 5.00 \\
\hline DSP & 0.00 & 1.00 & 5.00 \\
\hline TOP & 0.00 & 2.00 & $5.00 \dagger$ \\
\hline $\mathrm{CHA}, \mu \mathrm{g} / \mathrm{L}$ & 2.00 & 0,00 & 5.00 \\
\hline DOX & 5.50 & 3.00 & $5.00 \neq$ \\
\hline
\end{tabular}
Maximum Values for Agricultural Use

Abbreviations are defined in Table 2.

*The standards used are $\mathrm{NO}_{2}$ and $\mathrm{NO}_{3}$ for drinking water; $\mathrm{BOD}_{5}$, TON, and TOP for unrestricted irrigation; CHA for aesthetic use; and DOX for fisheries.

TTypical values adopted from Bouwer and Idelovilch [1987].

\$Typical values adopted from Soil Conservation Service [1992]. 
Table 5. Assumed Ranges of Flow Rates From Upstream, Point Source, and Nonpoint (Diffuse) Sources

\begin{tabular}{|c|c|c|c|c|c|}
\hline & \multirow[b]{2}{*}{ Variable } & \multicolumn{2}{|c|}{ Maximum Limit } & \multicolumn{2}{|c|}{ Minimum Limit } \\
\hline & & $\begin{array}{l}\text { Cubic Meters } \\
\text { per Second }\end{array}$ & $\begin{array}{c}10^{6} \text { Gallons } \\
\text { per Day }\end{array}$ & $\begin{array}{l}\text { Cubic Meters } \\
\text { per Second }\end{array}$ & $\begin{array}{c}10^{\text {f }} \text { Gallons } \\
\text { per Day }\end{array}$ \\
\hline \multicolumn{6}{|c|}{ Sewage Treatment Plant or Point Source Flow* } \\
\hline \multirow{2}{*}{\multicolumn{6}{|c|}{ Upstreamt $^{9.13}$}} \\
\hline & & & & & \\
\hline $\begin{array}{l}\text { Headwater } 1 \\
\text { Headwater } 2\end{array}$ & $\begin{array}{l}Q_{1}^{u} \\
Q_{2}^{u}\end{array}$ & $\begin{array}{l}1.05 \\
0.43\end{array}$ & $\begin{array}{r}23.97 \\
0.81\end{array}$ & $\begin{array}{l}0.95 \\
0.33\end{array}$ & $\begin{array}{r}21.68 \\
7.53\end{array}$ \\
\hline Headwater 3 & $\begin{array}{l}Q_{2}^{2} \\
Q_{3}^{\prime \prime}\end{array}$ & $\begin{array}{l}0.43 \\
0.19\end{array}$ & $\begin{array}{l}9.81 \\
4.34\end{array}$ & 0.09 & 2.05 \\
\hline & $Q_{i}^{u}$ & 1.67 & 38.12 & 1.37 & 31.26 \\
\hline \multicolumn{6}{|c|}{ Diffuse Sourcesț } \\
\hline Reach 1 & $Q_{1}^{d}$ & 0.0080 & 0.18 & & \\
\hline Reach 2 & $Q_{2}^{d}$ & 0.0025 & 0.06 & & \\
\hline Reach 3 & $Q_{3}^{d}$ & 0.0010 & 0.02 & & \\
\hline Reacls 4 & $Q_{4}^{d}$ & 0.0030 & 0.07 & & \\
\hline Reach 5 & $Q_{5}^{d i}$ & 0.0020 & 0.05 & & \\
\hline Reach 6 & $Q_{6}^{d}$ & 0.1167 & 2.66 & 0.0583 & 1.33 \\
\hline \multirow{2}{*}{ Reach 7} & $Q_{7}^{d}$ & 0.0060 & 0.14 & & \\
\hline & $Q_{i}^{d}$ & 0.1392 & 3.18 & & \\
\hline
\end{tabular}

*Decision variable in the S/O model within the given bounds.

$\dagger$ Fixed value in the $\mathrm{S} / \mathrm{O}$ model for generating a set of noninferior solutions.

tConstant base flow in all reaches except reach 6 , which receives OLF effluent as a nonpoint source. The fiow rate of reach 6 is a decision variable in the S/O model within the given bounds.

\subsection{Modeling Procedure and Results}

The procedure for developing regression equations and an optimal loading strategy for one scenario is discussed below (Figure 2). (A scenario is a unique management problem bcing solved. Changing the bound on objective 2 creates a new management problem and scenario to develop a noninferior solution.)

1. Assume three values for flow rate and concentration for each constituent in upstream, point, and nonpoint sources based on historical stream data and expected treatment effciencies of the STP and OLF systems (see Table 5 for ranges of flow rates used). Concentrations are ranged $\pm 20 \%$ over the expected values in the respective source/location.

2. Run QUAL2E for the unique assigned combination of flow rates and concentrations in upstream, point, and nonpoint sources.

3. Note results (flow rate and concentration of each constituent) at the control location for each simulation.

4. Perform multiple regression analysis on the results for each constituent. (Many forms of regression expressions were tested. Of these, the mass flow rate regression equation (4) was

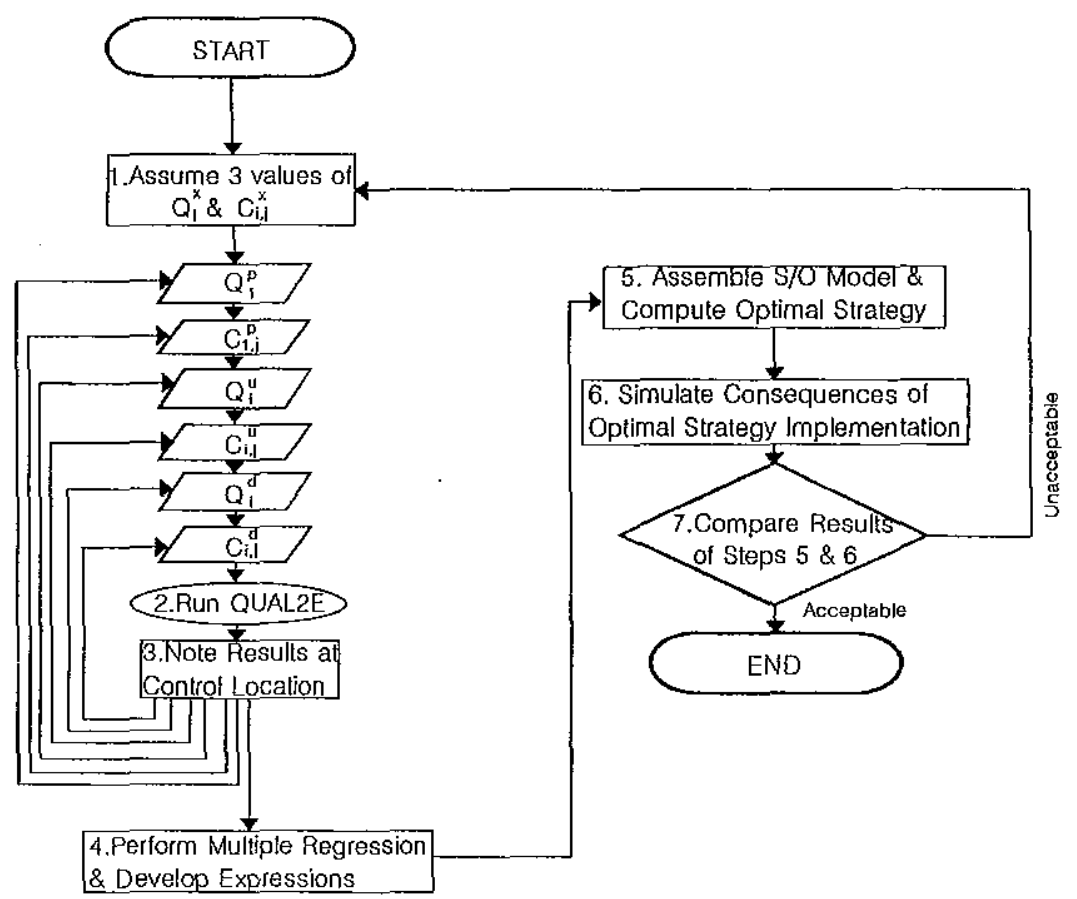

Figure 2. Flowchart of cycling process. 
the best for predicting the concentrations of all constituents except dissolved oxygen. Regression equation (5) was best for dissolved oxygen.)

Steps 2 and 3 are repeated systematically to carry out step 4, as shown in Figure 2. Loops around steps 2 and 3 can be imagined as six nested DO loops in a typical FORTRAN program. Processing in the two innermost loops is as follows. The innermost loop (for the variable $C_{i, j}^{d}$ ) shows that the concentrations of all the constituents in nonpoint sources are changed simultaneously and assigned assumed values three times while all other variables are held constant. Three simulation runs are made and recorded. Then, we go to the second innermost loop. Nonpoint source flow $\left(Q_{i}^{d}\right)$ values in all reaches are changed simultaneously and assigned their second assumed values. The innermost loop is completed as described. A total of 729 simulation runs are made.

5. Assemble the S/O model using appropriate coefficients and compute the optimal solution (equations (1) through (11)). Perform nonlinear optimization using the Modular Incore Nonlinear Optimization System (MINOS) solver [Murtagh and Saunders, 1987].

6. Simulate system response (concentrations of constituents at control location) to the optimal strategy using the QUAL2E model and compare results with those predicted by the S/O model.

7. Halt if the S/O model prediction is acceptably close to that of the QUAL2E model; othcrwise, return to step 1 and repeat the steps.

We term this seven-step procedure a cycle. It is followed to develop a single optimal strategy (a noninferior solution). To generate a noninferior solution set for one fixed set of upstream flow rates, we compute an optimal strategy for every value of $Z_{2}^{L}$, which is varied from $Z_{2}$ at max $Z_{1}$ to maximum $Z_{2}$.

A set of noninferior solutions is developed for a particular set of three headwater inflow rates $\left(Q_{1}^{\prime \prime}=1.00, Q_{2}^{n}=0.38\right.$, and $Q_{3}^{u}=0.14 \mathrm{~m}^{3} / \mathrm{s}$ ), which total $1.52 \mathrm{~m}^{3} / \mathrm{s}$ (Figure 1). This value of $Q_{i}^{\prime \prime}$ is the 7-day average minimum flow in the stream occurring once in 10 years (7Q10). This set of noninferior solutions contains point A2 in Figure 3.

Along this set of noninferior solutions (Figure 3), as the number of cows increases, the human population decreases (i.e., tight water quality constraints mean that an increase in loading in the OLF reach forces a decrease in loading from the STP), and vice versa. The slope of this set of noninferior solutions (the change in human population per unit change in number of cows) represents the trade-off between the two goals. The trade-off (constrained derivative, marginal, shadow price) is 95 persons per 100 cows in terms of waste load.

The selection of the best compromise solution is a decisionmaking process which can be aided by public representatives and applied techniques (for example, the surrogate worth trade-off method introduced by Haimes and Hall [1974] and extended by Chankong and Haimes [1978]) for plan selection. Assume that we select a best compromise solution (point $\mathrm{A}_{2}$ in Figure 3) which includes a population of 15,000 dairy cows (this decision variable represents a flow of $0.087 \mathrm{~m}^{3} / \mathrm{s}$ to the OLF system). Thus, the STP can discharge treated wastewater generated by a population of 108,689 persons at an upstream inflow of $1.52 \mathrm{~m}^{3} / \mathrm{s}$. For this best compromise solution, the STP discharge is $7.6 \times 10^{6}$ gallons/day $\left(0.33 \mathrm{~m}^{3} / \mathrm{s}\right)$. The optimal OLF design is $39.2 \mathrm{~m}$ long, $3000 \mathrm{~m}$ wide, and 1.76 ha in area and has a flow rate of $0.087 \mathrm{~m}^{3} / \mathrm{s}\left(2 \times 10^{6}\right.$ gallons/day $)$ and an

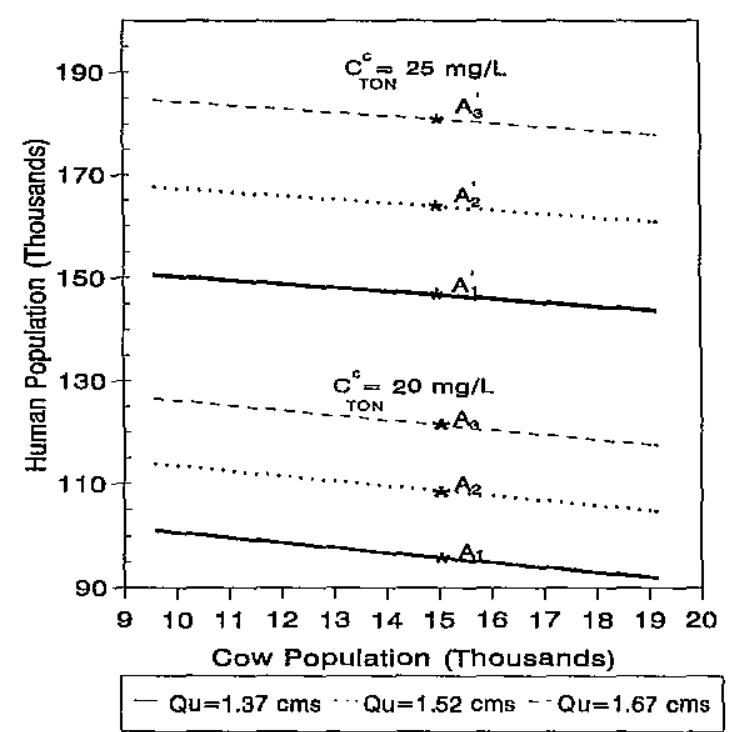

Figure 3. Sets of noninferior solutions (human versus dairy cow populations) as functions of upstream inflow rate and upper bound on total nitrogen permitted at a stream control location. Here cms denotes cubic meters per second.

application rate of $0.31 \mathrm{~m}^{3} \mathrm{~h}^{-1} \mathrm{~m}^{-1}$ for a $12-\mathrm{h} / \mathrm{d}$ application period.

It is useful to verify the accuracy of system responses computed by regression equations within the S/O model. Table 6 shows concentrations computed by the S/O model and those subsequently simulated by QUAL2E to result from the optimal loading strategy. The regression equation approach is acceptably accurate. Usually, only two cycles were needed for regression equations to satisfactorily predict system response. Table 7 statistically compares the constituent concentrations at the control location predicted by the S/O model with those subsequently simulated by QUAL2E.

\subsection{Sensitivity Analysis}

3.3.1. Sensitivity to nondeterministic upstream flow rate. The optimal dual-source waste loading strategies are calculated at an assumed nondeterministic upstream flow rate. The sensitivity of optimal strategies to upstream flow rates is demonstrated by changing the upstream flow rate by $\pm 10 \%$. Changing the value of the inflow rate allows additional sets of noninferior solutions to be developed for other inflow schemes. Figure 3 (lower part) also illustrates the sets of noninferior solutions developed for two other inflow schemes. These are constructed by using upstream flow rates of $Q_{i}^{u}=$ $1.37 \mathrm{~m}^{3} / \mathrm{s}\left(Q_{1}^{u}=0.95, Q_{2}^{u}=0.33\right.$, and $\left.Q_{3}^{u}=0.09 \mathrm{~m}^{3} / \mathrm{s}\right)$ and $Q_{i}^{u}=1.67 \mathrm{~m}^{3} / \mathrm{s}\left(Q_{1}^{u}=1.05, Q_{2}^{u}=0.43\right.$, and $Q_{3}^{u}=0.19$ $\mathrm{m}^{3} / \mathrm{s}$ ). Solutions $A_{1}$ and $A_{3}$ in Figure 3 show the sensitivity (11.7\%) of best compromise solution $A_{2}$ to the change in upstream flow. The respective supported human populations are 95,944 and 121,435 . These represent STP discharges of 6.7 $\times 10^{6}$ and $8.5 \times 10^{6}$ gallons/day, respectively. The optimal designs of OLF system are the same for these noninferior solutions $\left(A_{1}\right.$ and $\left.A_{3}\right)$ as for the best compromise solution $\left(A_{2}\right)$ since the number of cows (which determines the flow rate to the OLF system) is the same. Since these sets of noninferior solutions are parallel to the set of noninferior solutions derived at an upstream flow of $1.52 \mathrm{~m}^{3} / \mathrm{s}$, the trade-off is the same for each. 
Table 6. Optimal Strategies and Design of OLF System (Solutions $A_{1}, A_{2}$, and $A_{3}$ ) at Different Upstream Flow Rates

\begin{tabular}{|c|c|c|c|c|c|c|c|c|}
\hline \multirow[b]{3}{*}{ Constituent $(j)$} & \multirow{3}{*}{$\begin{array}{c}\text { OLF } \\
\text { Effluent } \\
\left(C_{6, j}^{d}\right)\end{array}$} & \multirow{3}{*}{$\begin{array}{c}\text { STP } \\
\text { Effluent } \\
\left(C_{1, j}^{p}\right)\end{array}$} & \multicolumn{6}{|c|}{ Value With Indicated Upstream Flow Rate $\left(C_{j}^{c}\right)$ at Control Location } \\
\hline & & & \multicolumn{3}{|c|}{ S/O Model } & \multicolumn{3}{|c|}{ QUAL2E } \\
\hline & & & $\begin{array}{l}1.37 \\
\mathrm{~m}^{3} / \mathrm{s}\end{array}$ & $\begin{array}{l}1.52 \\
\mathrm{~m}^{3} / \mathrm{s}\end{array}$ & $\begin{array}{l}1.67 \\
\mathrm{~m}^{3} / \mathrm{s}\end{array}$ & $\begin{array}{l}1.37 \\
\mathrm{~m}^{3} / \mathrm{s}\end{array}$ & $\begin{array}{l}1.52 \\
\mathrm{~m}^{3} / \mathrm{s}\end{array}$ & $\begin{array}{l}1,67 \\
\mathrm{~m}^{3} / \mathrm{s}\end{array}$ \\
\hline \multicolumn{9}{|c|}{ Concentrations } \\
\hline $\mathrm{BOD}_{5}, \mathrm{mg} / \mathrm{L}$ & 35.00 & 31.00 & 5.06 & 5.08 & 5.08 & 4.92 & 5.03 & 5.12 \\
\hline $\mathrm{OGN}, \mathrm{mg} / \mathrm{L}$ & 24.00 & 15.00 & 3.70 & 3.64 & 3.59 & 3.31 & 3.34 & 3.38 \\
\hline $\mathrm{NH}_{3}, \mathrm{mg} / \mathrm{L}$ & 36.00 & 32.00 & 8.94 & 8.99 & 9.03 & 8.90 & 8.96 & 9.00 \\
\hline $\mathrm{NO}_{2}, \mathrm{mg} / \mathrm{L}$ & 0.20 & 0.20 & 0.76 & 0.77 & 0.77 & 0.89 & 0.89 & 0.88 \\
\hline $\mathrm{NO}_{3}, \mathrm{mg} / \mathrm{L}$ & 11.81 & 9.17 & 6.59 & 6.60 & 6.61 & 6.55 & 6.50 & 6.47 \\
\hline TON, mg/L & 82.10 & 56.20 & $20.00^{*}$ & $20.00^{*}$ & $20.00^{*}$ & 19.65 & 19.69 & 19.73 \\
\hline OGP, mg/L & 16.00 & 3.00 & 0.74 & 0.72 & 0.71 & 0.72 & 0.72 & 0.72 \\
\hline $\mathrm{DSP}, \mathrm{mg} / \mathrm{L}$ & 10.80 & 5.60 & 2.67 & 2.67 & 2.66 & 2.79 & 2.78 & 2.76 \\
\hline TOP, mg/L & 26.80 & 8.62 & 3.41 & 3.39 & 3.37 & 3.51 & 3.50 & 3.48 \\
\hline $\mathrm{CHA}, \mu \mathrm{g} / \mathrm{L}$ & 3.00 & 4.00 & 3.07 & 3.08 & 3.09 & 3.03 & 3.03 & 3.02 \\
\hline $\mathrm{DOX}, \mathrm{mg} / \mathrm{L}$ & 4.00 & 3.00 & 6.12 & 5.94 & 5.81 & 6.80 & 6.70 & 6.60 \\
\hline \multicolumn{9}{|c|}{ Flows to Stream } \\
\hline Upstream $\left(Q_{i}^{u}\right), \mathrm{m}^{3} / \mathrm{s}$ & & & 1.37 & 1.52 & 1.67 & & & \\
\hline $\operatorname{STP}\left(Q^{D}\right), \mathrm{m}^{3} / \mathrm{s}$ & & & 0.29 & 0.33 & 0.37 & & & \\
\hline $\operatorname{STP}\left(Q_{1}^{p}\right), 10^{6} \mathrm{gal} / \mathrm{day}$ & & & 6.70 & 7.60 & 8.50 & & & \\
\hline OLF reach $\left(Q_{6}^{d}\right), \mathrm{m}^{3} / \mathrm{s}$ & & & 0.031 & 0,031 & 0.031 & & & \\
\hline OLF reach $\left(Q_{6}^{\sigma}\right), 10^{6} \mathrm{gal} / \mathrm{day}$ & & & 0.70 & 0.70 & 0.70 & & & \\
\hline
\end{tabular}

Abbreviations are defined in Table 2. Design of OLF land treatment system: length $(L)=39.20 \mathrm{~m}$; width $\left(W_{\text {design }}\right)=3000.00 \mathrm{~m}$; area $=$ $11.76 \mathrm{ha}$; flow rate $\left(Q^{d i}\right)=0.087 \mathrm{~m}^{3} / \mathrm{s}\left(2.00 \times 10^{5} \mathrm{gal} /\right.$ day $)$; application rate $\left(q^{\text {OLF }}\right)=0.31 \mathrm{~m}^{3} \mathrm{~h}^{-1} \mathrm{~m}^{-1}$; application period $\left(O_{\text {period }}\right)=12.00$ $\mathrm{h} / \mathrm{d}$.

*Tight bound.

3.3.2. Sensitivity to upper limit on constituent concentration. The three sets of noninferior solutions in the lower half of Figure 3 employ an upper limil of $20 \mathrm{mg} / \mathrm{L}$ total nitrogen concentration at the control location. This bound was always tight. Relaxing the tight total nitrogen (TON) upper bound permits more loading. Optimal strategy sensitivity to the TON bound is evaluated by running a new optimization with $25 \mathrm{mg} / \mathrm{L}$ as the upper bound. The results are shown graphically as three sets of noninferior solutions in the upper part of Figure 3 . Strategies for scenarios $A_{1}^{\prime}, A_{2}^{\prime}$, and $A_{3}^{\prime}$ permit population increases of $53 \%, 51 \%$, and $49 \%$ over those for $A_{1}, A_{2}$, and $A_{3}$, respectively. For these solutions, the nitrite concentration (1 $\mathrm{mg} / \mathrm{L}$ ) at the control location is the tight constraint. All other constituent concentration constraints are loose.

The new sets of noninferior solutions are more sensitive to

Table 7. Statistical Comparison Between the S/O Model Prediction and QUAL2E Simulation for Constituent Concentrations at the Control Location

\begin{tabular}{ccccc}
\hline $\begin{array}{c}\text { Constituent } \\
(j)\end{array}$ & $\begin{array}{c}\text { Mean } \\
\text { Difference, } \\
\%\end{array}$ & $\begin{array}{c}\text { Standard } \\
\text { Deviation, } \\
\%\end{array}$ & $\begin{array}{c}\text { Maximum } \\
\text { Difference, } \\
\%\end{array}$ & $\begin{array}{c}\text { Minimum } \\
\text { Difference, } \\
\%\end{array}$ \\
\hline BOD $_{5}$ & 0.18 & 1.69 & 3.64 & -2.56 \\
$\mathrm{OGN}$ & 7.79 & 2.79 & 12.92 & 3.53 \\
$\mathrm{NH}_{3}$ & 0.50 & $\mathbf{0 . 1 4}$ & 0.74 & 0.22 \\
$\mathrm{NO}_{2}$ & -9.00 & 4.72 & -2.91 & -14.77 \\
$\mathrm{NO}_{3}$ & 1.05 & 0.74 & 2.32 & -0.29 \\
TON & 1.50 & 0.25 & 1.99 & 1.11 \\
OGP & 0.31 & 1.74 & 2.99 & -2.63 \\
DSP & -2.70 & 1.26 & -0.64 & -4.71 \\
TOP & -2.05 & 0.84 & -0.99 & -3.23 \\
CHA & 0.83 & 0.98 & 1.99 & -0.63 \\
DOX & -10.91 & 0.81 & -9.51 & -12.42 \\
\hline
\end{tabular}

Summary of 24 runs. Abbreviations are defined in Table 2. the upstream flow rate (wider spacing between the curves in Figure 3) and have a waste load trade-off value of 71 persons per 100 cows. This is lower than the previous value of 95 persons per 100 cows, indicating that the two groups of sets of noninferior solutions are not parallel (although the distorted scale obscures that).

Other sensitivity analyses can be performed for a computed optimal strategy by standard approaches. Brown and Barnwell [1987] report procedures for Monte Carlo simulation, firstorder error analysis, and automated sensitivity analysis.

\section{Summary}

The S/O model presented determines maximum steady waste load allocations from point and nonpoint sources subject to downstream water quality constraints. To do this, it adequately represents surface water quality changes due to both loadings. The parameters considered are 5-day biochemical oxygen demand, dissolved oxygen, nutrients (nitrogen and phosphorus), and chlorophyll $a$. Of these constituents, nutrients and chlorophyll $a$ had not previously been incorporated in S/O models. Two new types of expressions for representing these constituent concentrations are presented. The DOX expression couples use of mass balance with concentrations of BOD, total nitrogen, and chlorophyll $a$ at the control location. The model simultaneously optimizes the design of the OLF land treatment system.

An important contribution is the development of a procedure that permits incorporating sophisticated water quality simulation via simplified equations. The use of simplified equations and an automated cycling procedure made the $\mathrm{S} / \mathrm{O}$ model simple and quick to solve and acceptably accurate compared with QUAL2E results.

The computed strategies and sets of noninferior solutions 
are most sensitive to unmanaged upstream inflow rates and constraints on downstream total nitrogen and nitrite concentrations. Increasing the upstream inflow rates or relaxing the concentration constraints can dramatically increase the supportable human and cow populations.

\section{Notation}

$Z_{1}$ principal objective representing human population.

$Z_{2}$ constraint objective representing number of cows.

$Z_{2}^{L} \quad$ lower limit on constraint objective.

$Q_{1}^{p}$ steady flow rate through the sewage treatment plant $\left(\mathrm{m}^{3} / \mathrm{s}\right)$.

$q^{p}$ per capita waste generation rate $\left(\mathrm{m}^{3} \mathrm{~s}^{-1}\right.$ capita $\left.^{-1}\right)$.

$Q^{d i}$ waste flow rate entering the overland flow treatment system $\left(\mathrm{m}^{3} / \mathrm{s}\right)$.

$q^{d i}$ unit flow rate generated in the dairy $\left(\mathrm{m}^{3} \mathrm{~s}^{-1}\right.$ (animal unit) $^{-1}$ ).

$f^{c u}$ conversion factor to convert animal units to number of cows.

$Q^{c}$ flow rate at the control location $\left(\mathrm{m}^{3} / \mathrm{s}\right)$.

$Q_{i}^{x}$ flow rate in the $i$ th component of $x$ th source/location $\left(\mathrm{m}^{3} / \mathrm{s}\right)$, where $x$ is superscript denoting diffuse $(d)$, upstream $(u)$, or point $(p)$ source.

$M_{i, j}^{x} \quad$ mass flow of the $j$ th constituent in the $i$ th component of $x$ th source/location ( $\mathrm{g} / \mathrm{s}$ or $\mathrm{mg} / \mathrm{s}$ ).

$M_{j}^{c} \quad$ mass flow of the $j$ th constituent at the control location ( $\mathrm{g} / \mathrm{s}$ or $\mathrm{mg} / \mathrm{s}$ ).

$C_{i, j}^{x} \quad$ concentration of the $j$ th constituent in the $i$ th component of $x$ th source/location $(\mathrm{mg} / \mathrm{L}$ or $\mu \mathrm{g} / \mathrm{L})$.

$C_{j}^{c}$ concentration of the $j$ th constituent at the control location $(\mathrm{mg} / \mathrm{L}$ or $\mu \mathrm{g} / \mathrm{L})$.

$\beta_{j}^{x} \quad$ regression coefficient describing the contribution of specific mass flow rate $\left(M_{i, j}^{x}\right)$ to $M_{j}^{c}$.

$k^{e}$ factor to take into account water lost from OLF system due to evapotranspiration and deep percolation.

$k^{t}$ factor to convert intermittent OLF operatjon into steady wastewater discharge to the stream in OLF reach.

$O_{\text {period }}$ application period for OLF system (h/d).

$W_{\text {cesign }}$ design width of the OLF system (m).

$q^{\text {OLF }}$ application rate to the OLF system $\left(\mathrm{m}^{3} \mathrm{~h}^{-1} \mathrm{~m}^{-1}\right)$.

FOS factor of safety.

$L$ length of OLF system.

$C_{j}^{\text {OLF }}$ concentration of the $j$ th constituent in the dairy wastewater to the OLF system (mg/L or $\mu \mathrm{g} / \mathrm{L}$ ).

$e_{j}^{p} \quad$ removal efficiency of the STP for the $j$ th constituent.

$e_{j}^{d} \quad$ removal efficiency of the OLF system for the $j$ th constituent.

$C_{j}^{\text {STP }}$ concentration of the $j$ th constituent in the domestic wastewater to the STP (mg/L or $\mu \mathrm{g} / \mathrm{L}$ ).

$C_{\mathrm{BOD}}^{\mathrm{BACK}}$ background concentration for OLF system.

$n, k, A$ empirical coefficients.

Acknowledgments. We appreciatc the programming aid of Alaa $\mathrm{H}$. Aly and the support of the Utah Agricultural Experiment Station. Approved as journal paper 4604.

\section{References}

Ahlfeld, D. P., J, M. Mulvey, and G. F. Pinder, Designing optimal strategies for contaminated groundwater remediation, Adv. Water Resour., 9(2), 77-84, 1986.
Alley, W. M., Regression approximations for transport model constraint sets in combined aquifer simulation-optimization studies, Water Resour. Res., 22(4), 581-586, 1986.

Bouwer, $\mathrm{H}_{\text {, }}$ and $\mathrm{E}$. Idelovitch, Quality requirements for irrigation with sewage water, J. Imig. Drain. Eng., 113(4), 516-535, 1987.

Brown, L. C., and T. O. Barnwell, The enhanced stream water quality models QUAL2E and QUAL2E-UNCAS: documentation and user's manual, Rep. EPA/600/3-87/007, U.S. Environ. Prot. Agency Environ. Res. Lab., Athens, Ga., May 1987.

Burn, D. H., Water quality management through combined simulation-optimization approach, J. Environ. Eng. N. Y., 115(5), 10111024, 1989.

Burn, D. H., and E. A. McBean, Optimization modeling of water quality in an uncertain environment, Water Resour. Res., 21(7), 934$940,1985$.

Cardwell, H., and H. Ellis, Stochastic dynamic programming models for water quality management, Water Resour. Res., 29(4), 803-813, 1993.

Chankong, V., and Y. Y. Haimes, Multi-Criteria Problem Solving, vol. 155, The Interactive Surrogate Worth Trade-off (ISWT) Method for Multiobjective Decision-Making, edited by S. Zionts, SpringerVerlag, New York, 1978.

Cohon, J. L., Mathematics in Science and Engineering, vol. 140, Multiobjective Programming and Planning, Academic, San Diego, Calif., 1978.

Cohon, J. L, and D. H. Marks, A review and evaluation of multiobjective programming techniques, Water Resour. Res., 11(2), 208-220, 1975.

Cooper, G. S., Optimal containment and recovery of light hydrocarbons in contaminated, unconfined aquifer, Ph.D. dissertation, 122 pp., Dept. of Biol. and Irrig. Eng., Utah State Univ., Logan, 1994.

Datta, B., and R. C. Peralta, Interactive computer graphics-based multiobjective decision-making for regional groundwater management, Agric. Water Manage., 11, 91-116, 1986.

DeLucia, R,, E. McBean, and J. Harrington, A water quality planning model with multiple time, pollutant, and source capabilities, Water Resour. Res., 14(1), 9-14, 1978.

Ellis, J. H., Stochastic water quality optimization using imbedded chance constraints, Water Resour. Res., 23(12), 2227-2238, 1987.

Elmore, T. J., J. Jaksch, and D. Downing, Point/nonpoint source trading programs for Dillion Reservoir and planned extensions to other areas, in Perspectives on Nonpoint Source Pollution, pp. 413-416, U.S. Environmental Protection Agency, Washington, D. C., 1985.

Gharbi, A., and R. C. Peralta, Integrated embedding optimization applied to Salt Lake valley aquifers, Water Resour. Res., 30(3), 817832, 1994.

Gorelick, S. M., and I. Remson, Optimal location and management of waste disposal facilities affecting ground water quality, Water Resour. Bull., 18(1), 43-51, 1982.

Gorelick, S. M., C. I. Voss, P. E. Gill, W. Murray, M. A. Saunders, and M. H. Wright, Aquifer reclamation design: The use of contaminant transport simulation combined with nonlinear programming, Water Resour. Res., 20(4), 415-427, 1984.

Greaves, G., G. B. Hatfield, and A. B. Winston, Mathematical programming for regional water quality management, Water Resour. Res., 8(2), 273-290, 1972.

Haimes, Y. Y., and W. A. Hall, Multiobjectives in water resources system analysis: The surrogate worth trade-off method, Water Resour: Res., IO(4), 615-623, 1974.

Lefkoff, L. J., and S. M. Gorelick, Simulating physical processes and economic behavior in saline, irrigated agriculture: Model development, Water Resour. Res., 26(7), 1359-1369, 1990.

Letson, D., Point/nonpoint source pollution reduction trading: An interpretive survey, Nat. Resour. J., 32, 219-232, 1992.

Letson, D., S. Crutchfield, and A, Malik, Point-nonpoint source trading for manlaging agricultural pollutant loadings, Agric. Econ. Rep. 674, U.S. Dept. of Agric. Econ. Res. Serv., Washington, D. C., 1993.

Liebman, J. C., and W. R. Lynn, The optimal allocation of stream dissolved oxygen, Water Resour. Res., 2(3), 581-591, 1966.

Loucks, D. P., and W. R. Lynn, Probabilistic models for predicting stream quality, Water Resour: Res., 2(3), 593-605, 1966.

Loucks, D. P., C. S. ReVelle, and W. R. Lynn, Linear programming models for water pollution control, Manage. Sci., 14, 166-181, 1967.

Loucks, D. P., J. R. Stedinger, and D. A. Haith, Water Resources Systems Planning and Analysis, Prentice-Hall, Engelwood Cliffs, N. J., 1981. 
Metcalf and Eddy Inc., Wastewater Engineering: Treatment, Disposal, and Reuse, 3rd ed., McGraw-Hill, New York, 1991.

Murtagh, B. A., and M. A. Saunders, MINOS 5.1 User's Guide, Rep. SOL 83-20R, Stanford Univ., Stanford, Calif., December 1983. (Revised January 1987.)

Peralta, R. C., M. A. Hegazy, and G. R. Musharrafieh, Preventing pesticide contamination of groundwater while maximizing irrigation crop yield, Water Resour. Res., 30(11), 3183-3193, 1994.

Shih, C. S., System optimization for river basin water quality management, J. Water Pollut. Control Fed, 42(10), 1792-1804, 1970.

Smith, R. G., and E. D. Schroeder, Field studies of the overland flow process for the treatment of raw and primary treated municipal wastewater, J. Water Pollut. Control Fed., 57(7), 785-794, 1985.

Soil Conservation Service, Agricultural Waste Management Field Handbook, U.S. Department of Agriculture, Landover, Md., February 1992.

Thomann, R. V., and J. A. Mueller, Principles of Surface Water Quality and Modeling and Control, Harper and Row, New York, 1987.

Thomann, R. V., and M. J. Sobel, Estuarine water quality management and forecasting, J. Sanit. Eng. Div. N. Y., 90(SA5), 9-36, 1964.
U.S. Environmental Protection Agency Office of Research and Development, Office of Water, Manual: Wastewater Treatment/Disposal for Small Communities, Rep. EPA/625/R-92/005, U.S. Environ. Prot. Agency, Washington, D. C., September 1992.

Water Pollution Control Federation, Natural Systems for Wastewater Treatment (Manual of Practice FD-16), Water Pollution Control Federation, Alexandria, Va., 1990.

Willis, R., and W. W.-G. Yeh, Groundwater Systems Planning and Management, 1st ed., Prentice-Hall, Englewood Cliffs, N. J., 1987.

M. S. Ejaz, Agricultural Engineering and Water Management, Agriculture Department, Government of Sindh, Karachi, Pakistan.

R. C. Peralta, Biological and Irrigation Engineering Department, Utah State University, Logan, UT 84322-4105.

(Received March 30, 1994; revised October 24, 1994; accepted November 11, 1994.) 